\title{
¿Perdidos en el laberinto? Husserl, Ortega y Gaos ante los desafíos de la diversidad cultural
}

\author{
Lost in the Labyrinth? Husserl, Ortega and Gaos confront the \\ Challenges of Cultural Diversity
}

JESÚS M. DÍAZ ÁLVAREZ*

\begin{abstract}
Resumen: Este artículo trata de mostrar la forma en que tres destacados filósofos del siglo XX Edmund Husserl, José Ortega y Gasset y José Gaos - han lidiado con la diversidad cultural. Ligados entre sí por fuertes vínculos intelectuales, los protagonistas del texto plantean tres modos diferentes de acercarse a este crucial y espinoso asunto en donde el papel asignado a la razón resulta de especial relevancia. Husserl confiará plenamente en ella. Ortega, incluso el Ortega más husserliano, abajará considerablemente tales pretensiones. Y Gaos, radicalizando las tesis perspectivistas de su maestro, considerará que es mejor asumir su impotencia. El juego de espejos que el ensayo pretende crear con el cruce de las tres propuestas quiere poner en valor la pertinencia de la filosofía hecha en español en los debates más acuciantes del presente.
\end{abstract}

Palabras clave: Diversidad cultural, racionalidad, razón histórica, Europa, Husserl, Ortega, Gaos.

\begin{abstract}
This article tries to show how three leading philosophers of the twentieth century --Edmund Husserl, José Ortega y Gasset and José Gaos- have addressed the issue of cultural diversity. Linked to each other by strong intellectual relations, the protagonists of the text will offer three different ways of approaching this crucial and thorny issue where the role assigned to reason is of special relevance. Husserl will fully trust her. Ortega, even the most Husserlian one, will lower such claims considerably. And Gaos, radicalizing the perspectivist theses of his teacher, will consider that it is better to assume her impotence. The game of mirrors that the essay tries to recreate with the crossing of the three proposals wants to value the relevance of the philosophy made in Spanish in the most pressing debates of the present.
\end{abstract}

Keywords: Cultural Diversity, Rationality, Historical Reason, Europe, Husserl, Ortega, Gaos

Recibido: 19/06/2019. Aceptado: 11/09/2019.

* Profesor Titular de Filosofía Moral y Política en la Facultad de Filosofía de la Universidad Nacional de Educación a Distancia, UNED (jdiaz@fsof.uned.es). El presente trabajo tiene su origen en la versión inglesa de una conferencia impartida el 18 de abril de 2011 en el The History of Philosophy Workshop de la Rice University. Quiero agradecer a los profesores Lane Kauffmann y Steven Crowell su amable invitación, y a todos los allí presentes sus punzantes y lúcidos comentarios. Tampoco puedo olvidarme de Jorge Brioso, quien ha sido durante tantos años compañero de discusión en muchos de los temas aquí abordados. Con Agustín Serrano de Haro sigo "disputando" amigablemente sobre la filosofía de José Gaos. Y me parece que, afortunadamente, queda para rato, porque la parte que a mí más me atrae y defiendo es la que a él le resulta más problemática y, en cierto modo, inasumible. José Luis Villalaín siempre está dispuesto a leer los textos que le envío con más paciencia de la que merezco, haciéndome sugerencias y correcciones pertinentes. Por último, y como no podía ser de otro modo, mi impagable gratitud a Gema y Antón. Este ensayo se ha elaborado en el marco del proyecto de investigación FFI2016-77009-R. 


\section{Introducción. Mapas para el laberinto}

En el año 2001, la Conferencia General de la UNESCO aprobó la Declaración Universal sobre la Diversidad Cultural. En ella, y en analogía con el concepto de biodiversidad, se establecía en su artículo 1 - La diversidad cultural patrimonio común de la humanidad-que "[...] la diversidad cultural es tan necesaria para el género humano como la diversidad biológica para los organismos vivos". Más allá de las dudas teóricas que pueda sugerir la analogía entre diversidad biológica y diversidad cultural, semejante declaración tiene importancia porque no hace otra cosa que plasmar claramente el triunfo de la idea de diversidad en las sociedades contemporáneas. Tras siglos de predominio del monismo cultural, de asumir la idea de que solo se puede ser plenamente humano de una sola forma, es preciso reconocer que el pluralismo se ha abierto paso como creencia común, al menos en occidente y en la teoría.

El problema es que el estallido del monismo y la celebración de la diversidad ha producido, junto a enormes e indudables beneficios, ciertos "daños colaterales". En efecto, aceptar el hecho de que la humanidad se declina irremediablemente en plural ha dado paso, no pocas veces, a una cierta ideología difusa que Fernando Savater ha denominado idolatría de la diversidad (https://elpais.com/diario/2004/07/01/opinion/1088632807_850215.html). Tal idolatría no es otra cosa que la penúltima enunciación de una vieja doctrina, el relativismo. El idólatra profesante sostiene que la diversidad cultural es un valor en sí mismo. Pero si esto es así, se incapacita, en principio, para distinguir entre, si se me permite la expresión, la buena y la mala diversidad. Y es que existen muchas prácticas culturales que nos resultan profundamente inmorales porque violan la igualdad, la libertad y la dignidad de las personas. La mutilación genital u otras discriminaciones por razón de sexo, color de la piel o religión son muy comunes en todas las culturas. Son prácticas que tienen sentido, "buen" sentido, dentro de los sistemas de creencias que las sustentan, pero no por ello pensamos que deberían ser asumidas o toleradas. Desde esta perspectiva, si lo que el idólatra cultural está pretendiendo hacer con su celebración irrestricta de la diversidad es defender una comunidad de humanos tolerantes y respetuosos, debería abandonar el relativismo como compañero de viaje. La exaltación pura de las diferencias es un camino tan recto hacia la barbarie como el monismo más dogmático, al no permitirnos hacer juicios razonables sobre qué diferencias son buenas o, cuando menos, inocuas, y cuáles no.

Dado el panorama anterior, creo que en nuestras crecientes sociedades multiculturales nos enfrentamos, pues, a la siguiente situación. La mayoría de nosotros somos pluralistas - o al menos nos tenemos por tales--, pensamos que la diversidad cultural es una riqueza que debemos preservar porque no existe una única forma de vivir una vida plena. Pero también somos conscientes de que hay muchas prácticas culturales degradantes e inaceptables. El problema es que tanto sobre lo primero como sobre lo segundo hay una gran disparidad de opiniones que muchas veces son contradictorias. No es fácil ponerse de acuerdo ni sobre las diversas formas de vida buena asumibles ni sobre aquello que debemos descartar como intolerable; y más teniendo en cuenta que la cultura occidental ha estado plagada de imposiciones y violencia ejercidas en nombre de la Verdad, la Libertad, el Bien, la Justicia o

1 Sobre la totalidad de la declaración, incluido el presente artículo, cf., http://portal.unesco.org/es/ev.php-URL_

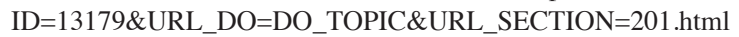


Dios, con mayúsculas² ¿Cómo saber, entonces, que cuando estamos tildando algo de "mala diversidad", de intolerable, no estamos proyectando nuestros prejuicios más acendrados e insostenibles o, simplemente, nuestras propias creencias particulares, y conculcando la libertad de los demás? ¿Cómo evitar que la necesaria defensa de la riqueza y variedad culturales se solape con el puro e insostenible relativismo? ¿Cómo orientarse, en fin, en el creciente laberinto cultural en el que se han convertido nuestras sociedades tardomodernas?

En las páginas que siguen, trataré de mostrar algunos de los mapas que para moverse en este laberinto dibujaron tres importantes filósofos del siglo XX: Edmund Husserl, José Ortega y Gasset y José Gaos. Tales mapas tendrán como protagonista a la razón y las posibilidades que ella nos ofrece para andar nuestro camino. Husserl confiará plenamente en su poder. Ortega, por lo menos hasta los años 30, tocará una melodía de tonalidades husserlianas, aunque abajará su fuerza con grandes dosis de historicidad y contingencia. Y Gaos desarrollará de modo radical algunas de las tesis perspectivistas de su maestro y proclamará, en una línea que se me antoja en ciertos aspectos muy parecida a la emprendida por Rorty o Vattimo, que es mejor asumir su impotencia ${ }^{3}$.

\section{Edmund Husserl. El proyecto de Europa y la diversidad cultural}

En la fenomenología husserliana, el concepto de mundo de la vida ocupa un lugar central. Tal concepto, que ha hecho fortuna en la filosofía y sociología contemporáneas y que, en contra de una creencia bastante generalizada, no procede de lo que se ha dado en llamar el "último Husserl", está atravesado, como otros igualmente esenciales en esa filosofía, por amplias tensiones, distando mucho de ser unívoco ${ }^{4}$. Una de sus acepciones fundamentales, que es la que ahora me interesa resaltar, entiende el mundo de la vida como Kulturwelt, es decir, como mundo cultural. Y no hace falta más que echar un somero vistazo a semejante mundo para ver que no es uno, sino muchos. La cultura se declina en plural - las culturas-y así lo atestiguan no solo nuestra más inmediata experiencia, sino la ingente producción

2 El muy querido y recientemente fallecido Javier Muguerza insistió en numerosas ocasiones en la necesidad de “apear de las mayúsculas a esas grandes palabras heredadas". En su opinión, que hago mía, esa era, quizá, la gran enseñanza que nos habían dejado las múltiples y sin par atrocidades del siglo XX. A este respecto, creo que cabe decir sin forzar mucho las cosas, que todo el pensamiento de este decisivo filósofo de la España contemporánea ha girado sobre cómo es posible seguir hablando razonablemente y a escala humana, es decir, en minúsculas, de las grandes palabras de la filosofía. Para estos asuntos, cf., Muguerza, 1998b, 207-208, y de modo más específico, Muguerza, 1991, 9-36.

3 La progresión historicista del autor de Meditaciones del Quijote me parece que es clara a medida que baja, entre otras cosas, su influencia husserliana. En este sentido, y teniendo en cuenta que no es fácil establecer períodos rígidos a la hora de leer su obra — por eso prefiero hablar de 'preponderancias'—, creo que es posible defender que por lo menos desde mediados de los años 30 en adelante cabe hablar de un giro historicista en su pensamiento que lo acercará en muchos aspectos a Gaos. Sobre el mencionado giro, que supone un alejamiento de la fenomenología husserliana y una aproximación a tesis hermenéuticas, ver Díaz Álvarez/Brioso, 2018, 373-386.

4 Sobre este asunto y sobre la temática de esta parte he escrito unos cuantos trabajos. De modo general me permito remitir a Díaz Álvarez, 2003 y Días Álvarez, 2015, 81-105. También se leerán con gran provecho, y me limito solo al ámbito español, los trabajos de Javier San Martín, Agustín Serrano de Haro, Miguel García-Baró, Francesc Pereña, Carmen López o Alicia de Mingo. Cf., por ejemplo, y entre muchos otros, San Martín, 2007; Serrano de Haro, 2011, 9-22; García-Baró, 2015, 7-84; De Mingo, 2017; Pereña, 2012, 177-191; López Sáenz, 2015, 117-138. 
histórica y antropológica. La variabilidad cultural es enorme y va desde nuestra manera de vestir o el modo en que nos comportamos en la mesa hasta nuestros sistemas de valores o los dioses en los que creemos. Fácticamente nos enfrentamos, por tanto, a la pluralidad cultural. Y tal cosa es reconocida y asumida sin ambages por Husserl. Pero una vez constatada la diversidad de mundos, el padre de la fenomenología dará un paso más y se preguntará si la diferencia radical entre ellos es la última palabra que podemos decir con sentido sobre los mismos, no quedándonos más remedio que asumir necesariamente que todos tienen igual valor, que todas las culturas son igualmente legítimas.

Como es de sobra conocido, esa es la tesis que mantienen los relativistas o idólatras culturales, por usar la expresión de Savater. Según ellos, señala Husserl certeramente en un texto del Origen de la geometría, "todo pueblo o grupo tiene su mundo en el que todo concuerda, tanto si es en la forma mágico-mítica como en la racional-europea, y todo se deja explicar completamente. Todo <pueblo> tiene su "lógica" y, según eso, si esta se explicitara en proposiciones, 'su' a priori” (Husserl, 1976, 382). Desde esta perspectiva no es posible, en efecto, establecer ninguna jerarquía racional entre mundos. Cada pueblo o grupo humano, como bien se nos dice, tiene su lógica, su a priori, en suma, $s u$ propia racionalidad a todos los efectos, su cultura, que nunca puede ser evaluada desde un tipo de horizonte ajeno al propio campo cultural. En este sentido, y como se nos manifiesta claramente en el fragmento anterior, la forma "racional-europea" no es, valorativamente hablando, ni mejor ni peor que la "mágico-mítica". Tampoco desvela más o menos verdades teóricas sobre los humanos y el mundo que les rodea. Y es que desde esta posición, cualquier sentido que le queramos atribuir a nociones como las de verdad, justicia, bien o belleza — por citar solo algunas de las que entendemos como cruciales en la mayoría de las culturas- solo adquiere validez dentro de cada uno de los mundos en los que emerge.

Pues bien, no es en absoluto exagerado decir que la fenomenología husserliana es una de las respuestas más potentes que la filosofía del siglo XX ha dado al escepticismo y sus aliados más o menos naturales, el relativismo y el historicismo. Veámoslo de modo rápido en una de las múltiples narraciones que Husserl hace al respecto.

Según la cita del Origen de la geometría recogida más arriba, el autor de La crisis de las ciencias europeas va a dividir las culturas en dos grandes bloques. A un lado colocará aquellas que caen bajo el rótulo de "racionalidad europea". Al otro, las subsumidas en eso que de forma un tanto amplia e imprecisa denomina "racionalidad mágico-mítica", y que en otros lugares, por ejemplo en su justamente celebrada Conferencia de Viena, tilda como racionalidad de carácter práctico, mítico-religiosa o pre-filosófica (cf., Husserl, 1976, 329). Con semejante macrodivisión, su intención profunda es resaltar el carácter singular, distintivo, específico de la racionalidad europea frente a cualquier otra. Y la pregunta lógica es, entonces, ¿cuál es propiamente esa peculiaridad que definiría de modo tan pregnante y claro a la cultura y racionalidad europeas? O puesto de otra forma, ¿qué constituye de manera tan radical la identidad de la cultura europea para separarla absolutamente del resto, cuajando un tipo verdaderamente único en su especie?

Antes de ver la respuesta husserliana a esta crucial cuestión o, mejor dicho, como preámbulo necesario para hacerse cargo de la respuesta, es preciso tener en mente que cuando el fundador de la fenomenología habla de Europa, o de cultura y racionalidad europeas, no designa un lugar geográfico. Europa, y por tal hay que entender el conjunto de occidente, 
es lo que comúnmente se comprende como una categoría espiritual, una forma peculiar de mirar el mundo que, en efecto, nació en semejante zona geográfica, de la que recibe su nombre, pero que en absoluto es exclusiva, propia o solo representativa del humano europeo. Pero, ¿qué puede ser aquello que ha nacido en Europa y, a la vez, no representa solo un modo de vivir particularmente europeo? ¿Qué mirada "europea" trasciende la particularidad de Europa? A juicio de Husserl, la que inaugura la filosofía alrededor del siglo VI antes de Cristo. Para el autor de Meditaciones cartesianas, igual que para muchos otros filósofos antes que él, filosofía y Europa, como categoría espiritual, van íntimamente ligadas porque el surgimiento de aquella en el viejo continente opera una transformación radical en la manera de vivir y pensar que llevaban hasta la fecha los europeos --tan particular por entonces como cualquier otra. ¿Y qué incorpora la mirada filosófica que la hace absolutamente nueva? Pues algo muy sencillo de enunciar y complicado de articular: conducir la vida según un ideal de racionalidad universal, de razón común válida para cualquiera por el mero hecho de ser un humano. En suma, al decir de Husserl, es esa idea de racionalidad que se quiere "neutra" e inclusiva de todo lo verdaderamente humano, que supuestamente descarta cualquier tipo de apellido o particularidad, lo que emerge de modo inaugural en Grecia de la mano de la filosofía y lo que distingue a la cultura europea de cualquier otra, pues solo en ella se ha convertido en tradición, bien es verdad que de modo quebrado y a veces con grandes retrocesos, este afán "ilustrado-racional".

Contemplado de esta forma, el Kulturwelt europeo sería el único en el que se daría, en efecto, la curiosa paradoja de pretender trascender de modo absoluto y hasta sus últimas consecuencias el propio marco espacial y temporal, al querer descartar todo lo particular, todo lo que está ligado al tiempo (Zeitgebunde). Encarnaría, así, un tipo peculiar de tradición hasta ese momento desconocida, "la tradición de la in-tradición", como señala Ortega en una bella y lúcida frase (Ortega y Gasset, 2006b, 159). Por eso, en esta forma mentis algo no adquiere validez por ser tildado de europeo sin más. El criterio de legitimidad no está vinculado a un grupo, época o conjunto de creencias no sometidas a examen en las que se vive de modo más o menos confortable y tradicional, sino que algo se valida como verdadero, bueno, bello o justo porque es el fruto de los mejores argumentos que pueden ser asumidos por cualquiera en el ejercicio honesto y publico de la razón, como diría Kant. En tal sentido —y permítaseme que insista en esta idea ya esbozada, pues es capital en la argumentación husserliana — la cultura europea no se ajustaría al patrón observado en cualquier otra y se diferenciaría completamente del resto. Su modo de articularse, al menos en un sentido ideal, no sería hacia dentro, hacia el grupo, pueblo, nación o colectividad que posee de modo reverencial un conjunto de creencias, sino hacia afuera. Es decir, no se trata de proteger o apuntalar a toda costa los "dogmas" heredados, sino de mantenerlos abiertos y en permanente revisión, dejando persuadirse por un constante dar y recibir razones, un permanente logon didonai nunca cerrado pero que tesaurizaría saberes teóricos y prácticos y desvelaría de modo asintótico un telos sobre la totalidad normativa y veritativa de lo humano.

Por lo visto hasta aquí, no es de extrañar que Husserl designe a la cultura europea --en este sentido normativo, categórico-espiritual-- no sólo como cultura de la idealidad, de aquello que no está ligado al tiempo, de la theoria o la crítica, sino también, y en íntima relación con ello, como la cultura de la autonomía y la absoluta responsabilidad del sujeto (cf., Husserl, 1976, 314-348). 
En conclusión, y resumiendo la posición del fundador de la fenomenología con respecto a la diversidad cultural, tenemos lo siguiente. Para Husserl, la cultura europea, occidente --en ese sentido peculiar que he explicitado- es la norma desde la que evaluar el resto. La razón fundamental estriba en que con ella nos hallamos frente a lo que James Hart ha llamado, siguiendo la estela del autor de La crisis, el paso de la racionalidad de las culturas a la cultura de la racionalidad (cf., Hart, 1992, 643-664)5. En efecto, el occidente del que habla Husserl, más que un conjunto de prácticas culturales, es una actitud, una nueva forma de ver el mundo que se basa en la razón como ideal. Sólo desde esta posición intelectual y vital es posible asistir a la verdadera escucha del diferente en pie de igualdad y dirimir nuestros conflictos culturales o de cualquier otro tipo sin recurrir a la imposición o la violencia. Por eso calificará a Europa de proyecto y lo presentará como telos de la humanidad, un viaje infinito al que deberían contribuir y sumarse las demás culturas ${ }^{6}$.

\section{José Ortega y Gasset. La diversidad cultural ante los dos movimientos de la razón histórica (lectura mínima de Las Atlántidas)}

En un excelente texto de 1924 titulado Las Atlántidas ${ }^{7}$, José Ortega y Gasset sigue una estrategia parecida a la de Husserl a la hora de enfrentarse a la diversidad cultural. Tal estrategia consiste en abordar este tema a partir de la realización de un diagnóstico de la cultura, "alma" o identidad europea.

Según el pensador madrileño, en los siglos XVIII y XIX, y de la mano del racionalismo en sus diferentes variantes, se impone la idea de que la cultura europea es la encarnación de lo humano y que el resto de formas de vida son sólo relevantes en la medida en que han contribuido a llegar al cenit europeo. Los siglos XVIII y XIX son, dice Ortega, "unitaristas" (Ortega y Gasset, 2005, 762), sin sensibilidad para la diferencia y la pluralidad. Esto es tan así, que una ciencia como la historia, destinada, entre otras cosas, a registrar los cambios, fracasó completamente en ese empeño porque los historiadores estaban imbuidos de una idea que el filósofo va a tildar como falsa. A saber, que la humanidad se declina en singular, que existe algo así como un concepto homogéneo y a priori de lo que sea la humanidad y que Europa está en posesión del mismo. La radicalidad orteguiana en este punto es tal que llega

5 Sobre este punto ha insistido mucho, entre nosotros, Javier San Martín. Ver, por ejemplo, San Martín, 2007, 221-238.

6 El 'Proyecto de Europa' ha sido tildado de eurocéntrico e incluso de racista. Jacques Derrida en su obra De l'esprit: Heidegger et la question lanzó un fortísimo ataque a la idea husserliana en este sentido. En España, Reyes Mate recogió la tesis en su libro Heidegger y el judaísmo. Y sobre la tolerancia compasiva. Por mi parte me ocupé del tema en varios textos (cf., por ejemplo, Díaz Álvarez, 2007, 157-169). En el momento presente, sigo pensando que, pese a los problemas que pueda presentar la idea de Europa como categoría y poder espiritual —entre ellos, por ejemplo, el que afecta a su supuesta neutralidad o a su también supuesta capacidad de totalización de lo humano-, es profundamente injusto acusar a Husserl de eurocéntrico, no digo ya de racista, si por tal se entiende un tipo de ideología que podría amparar o legitimar de algún modo el dominio sobre los no occidentales o cualquier negación o minusvaloración de su humanidad.

7 La reflexión que ahora realizo sobre la diversidad cultural en Ortega se centrará exclusivamente en una lectura interpretativa y bastante libérrima de Las Atlántidas. En otros lugares he ofrecido narraciones sobre el particular articuladas de un modo diferente, aunque complementario. Cf., Díaz Álvarez, 2012, 109-128. Para una edición reciente, informativa y recomendable del escrito orteguiano cf., Ortega y Gasset/Carriazo, 2016. Resulta también de interés, De Haro Honrubia, 2012, 217-240. 
a sostener que el gran fallo de los pensadores liberales, marxistas o darwinistas, es decir, de aquellos que han acuñado las creencias matriz de la cultura europea del momento, consiste en sostener que "la estructura esencial de la vida humana ha sido siempre idéntica" (Ibídem., 768), que las categorías de la mente humana han sido siempre las mismas (cf., Ibídem., 770); en suma, que el africano, el hindú o el habitante de la antigua Roma son esencialmente igual que nosotros, sólo que en un estadio inferior de desarrollo técnico y moral. Pensar de tal modo es un profundo error y renunciar a entender verdaderamente al otro.

Parece, pues, que Ortega igual que alguna de la mejor filosofía contemporánea ${ }^{8}$, no nos quiere ahorrar la incomodidad del diferente, el confrontarnos con la perplejidad que supone que una cultura distinta impugne de modo radical nuestras creencias más profundas y evidentes. En fin, no quiere pasar de puntillas sobre el hecho bruto de la diversidad humana, cuya negación ha estado no pocas veces en la raíz de la violencia que hemos ejercido sobre los no occidentales. El caso del colonialismo y sus desastrosas consecuencias así lo atestigua. Semejante posición le lleva a propugnar el interesante concepto de "historia universal policéntrica" (Ibídem., 764-766), una nueva forma de practicar esta ciencia que se encargaría, al modo que lo hace la antropología cultural en la actualidad, de reconstruir el sentido producido por las culturas no europeas. O lo que es lo mismo, de entender sus sistemas de creencias desde sí mismas y no como un medio para o un escalón hacia el tipo superior de cultura que sería occidente.

Hay que reconocer sin ambages que esta historia universal policéntrica, esta reconstrucción del sentido, que también calificará como primera dirección o movimiento de la razón histórica, dignifica, ciertamente, a las otras culturas, las trata de igual a igual; es, ciertamente, policéntrica. Es decir, no hay aquí jerarquías; no hay unas producciones de sentido que se juzguen como mejores que otras; simplemente son diferentes. Las diversas tradiciones mandan, constituyen las identidades de los individuos y los pueblos y sólo desde ellas es posible emitir juicios. Este movimiento de la razón histórica, el propio Ortega así lo expresa, es claramente relativista (cf., por ejemplo, Ibídem., 769).

Sin embargo, el interés que presenta el planteamiento de Ortega, igual que el de Husserl, es que, tras este reconocimiento irrestricto de la diversidad, no se queda en ese primer movimiento reconstructivo de la razón histórica, sino que intenta desarrollar una segunda dirección de la misma, un segundo movimiento que aun haciéndose cargo del carácter contingente e histórico de los humanos, de ese estar enmarcados en diversas culturas y tradiciones, trata de superar la pura relatividad, la pura diferencia, la mera pluralidad que iguala sin más a todas las culturas.

En Las Atlántidas, Ortega enuncia el segundo movimiento de la razón histórica del siguiente modo: "Pero no basta, para acercarse a su plenitud, con que el sentido histórico perciba esas profundas diferencias que ha presentado el alma humana a lo largo del tiempo. Cuando hayamos entendido agudamente cada época y cada pueblo en su personalidad diferencial, no habremos agotado la posible perfección de la sensibilidad histórica. Es menester

8 Cf., al respecto, Muguerza, 1998a, 7-41. Este escrito de Muguerza, que lleva por significativo título El puesto del hombre en la cosmópolis, es una brillante discusión propositiva de algunas de las tesis filosóficas contemporáneas más relevantes sobre la "incomodidad del otro". A este respecto, y del mismo autor, es también muy recomendable, Muguerza, 2009, 9-25. Sobre Muguerza y Ortega, con José Gaos entre medias, cf., Muguerza, 2010, 56-81. 
que de esta fina comprensión se saquen consecuencias de orden estimativo. [Y un poco más adelante sostiene enfáticamente] La valoración de las distintas culturas, su jeraquización en una escala de rangos, supone la previa comprensión de todas ellas" (Ibídem., 771).

Tenemos entonces que estimar, que emitir un juicio sobre las diferentes culturas, pero, ¿cómo hacerlo, desde dónde? ¿Cómo evaluar desde una perspectiva -en el fondo una manifestación particular de lo humano- el resto de puntos de vista? ¿No se está postulando con ello algo de lo que Ortega siempre renegó, a saber, el ojo de Dios, la para él imposible perspectiva absoluta? En este punto, la apuesta del pensador madrileño pasa —y en esto muestra, como en muchos otros aspectos centrales de su filosofía, ser un buen fenomenólogo-- por mirar detenidamente la realidad, mejor dicho, las diversas realidades que nos muestran las diferentes culturas. Y qué descubrimos cuando hacemos tal ejercicio. Primero, que "cada cultura ha gozado de alguna genialidad sobresaliente para algún tema vital” (Ibídem., 771). Las culturas asiáticas, por ejemplo, han desarrollado un profundo sentido de la compasión y técnicas para el control y ordenamiento de los deseos que no tienen parangón en occidente. $\mathrm{Su}$ aspiración a la eliminación del individuo, siendo un proyecto completamente opuesto al europeo, no deja de tener aspectos positivos de los que deberíamos aprender en sociedades, las nuestras, en las que el paroxismo individualista se ha transformado muchas veces en puro e irracional capricho. Destacando la genialidad de las diferentes culturas, Ortega vaticinará un "nuevo clasicismo" (Ibídem., 771), uno de verdad y no impostado, construido con las aportaciones de las diferentes tradiciones. Cada pueblo, sostendrá, se convertirá en un clásico al tocar de modo verdadero sucesivas porciones de lo real.

Ahora bien, teniendo esto presente, una pregunta se hace inevitable, ¿cuál es la característica más sobresaliente de Europa en esa mirada policéntrica?, ¿cuál es la gran aportación de occidente al mundo? Pues precisamente el reconocimiento de la pluralidad y lo que ella supone. Dice el pensador madrileño: "La Historia [y aquí hay que tener en mente que historia es razón histórica] al reconocer la relatividad de las formas humanas, inicia una forma exenta de relatividad. Que esta forma aparezca dentro de una cultura determinada y sea una manera de ver el mundo surgida en el hombre occidental no impide su carácter absoluto. El descubrimiento de una verdad es siempre un suceso con fecha y localidad precisas. Pero la verdad descubierta es ubicua y ucrónica. La Historia es razón histórica, por tanto, un esfuerzo y un instrumento para superar la variabilidad de la materia histórica" (Ibídem., 772). ¿Pero por qué es el descubrimiento de la pluralidad humana el inicio de un tipo de mirada exenta de relatividad? Pues porque sólo a partir de ella, sólo sintiendo la punzada del otro, puedo darme cuenta de los límites de mi propia tradición; puedo empezar a pensar que quizá yo o mi comunidad estemos equivocados, en suma, puedo experimentar el filosófico fastidio de que para una misma pregunta las múltiples tradiciones hayan dado diferentes respuestas no compatibles entre sí. Para llegar a eso, es necesario hacerse cargo de la pluralidad. Esto es, por otra parte, lo que jamás podrá experimentarse desde una posición netamente relativista. El representante de esta tradición no parece sentirse perplejo o mostrar inquietud ante la diversidad; no tiene ningún problema con ella, y Ortega, muy lúcidamente, parece decir que ello es así porque este tipo de mirada no es sino un unitarismo dogmático multiplicado por el número de culturas que podamos encontrar. Desde esta óptica, cada cultura se considera la cultura que siempre verá a las demás exclusivamente en función de sí misma. 
Occidente ha cometido muchas veces ese error, asume el autor español, pero hasta donde sabemos parece ser la única perspectiva que ha intentado trascender de modo sistemático y articulado esa limitación y acoger la incómoda mirada del otro. Y eso, precisamente, es lo que la haría "superior" a las demás. El pensador madrileño lo expresa de la siguiente forma: "Hay una cultura china y una cultura malaya y una cultura hotentote, como hay una cultura europea. La única superioridad definitiva de ésta habrá de ser reconocer esa esencial paridad antes de discutir cuál de ellas es superior. El hotentote, en cambio, cree que no hay más cultura que la hotentote" (Ibídem., 757).

En definitiva, la inteligente tesis que Ortega está sosteniendo es que no tenemos que salir del ámbito de la experiencia para iniciar ese segundo movimiento de la razón histórica, el que se ocupa con la jerarquización de las culturas. Sin recurrir, en principio, a supuestos metafísicos, seríamos capaces de percibir que el genio del mejor occidente termina siendo una actitud, una perspectiva que se muestra más englobante que las anteriores porque acoge de un modo peculiar el resto de perspectivas $-\mathrm{y}$ la suya propia - y las termina poniendo en diálogo, en fricción; es decir, las termina considerando desde un punto de vista crítico.

Resumamos lo esencial. Tenemos en Ortega dos movimientos, o como él manifiesta, dos direcciones de la razón histórica. El primero es de reconocimiento de la pluralidad, la famosa "historia universal policéntrica", en la que reconstruimos sin jerarquizarlo el sentido humano de todas las culturas. El segundo tiene carácter estimativo, jerarquizador, evaluativo, y se construye a partir de la puesta en práctica de ese primer movimiento y de la actitud que lo alienta. Si en un primer momento la razón histórica es "relativista", en el segundo es propiciatoria de una tensión necesaria y constante entre la unidad y la pluralidad.

Si reparamos brevemente en lo dicho por Ortega, su melodía suena en pasajes importantes parecida a la husserliana. Ambos consideran a occidente una vara con la que medir la diversidad cultural. Pero una vez más, el occidente del que hablamos es un occidente filosófico, un occidente que cuaja en una actitud, en una forma de mirar el mundo que se asienta en la posibilidad de razonar, de argumentar, en la crítica, en la autonomía, en la libertad. Dejo alguna de las diferencias entre la racionalidad husserliana y la orteguiana, incluso la del Ortega más fenomenólogo, para el apartado final de este ensayo.

\section{José Gaos. De la soberbia filosófica a la filosofía de la melancólica serenidad. El debili- tamiento del pensar frente a la diversidad cultural}

José Gaos, como es de todos conocido, ha sido uno de los más destacados discípulos de Ortega y Gasset y uno de los integrantes, junto con Manuel García Morente, Xavier Zubiri, María Zambrano, Manuel Granell, Antonio Rodríguez Huescar o Julián Marías, entre otros, de la así llamada 'Escuela de Madrid', una generación de brillantes filósofos españoles que se constelaron entorno a la figura de Ortega y que quedó trágicamente rota por la cruel y desgraciada Guerra Civil española de 1936. Esta ruptura impidió una recepción normalizada de sus respectivos pensamientos en las generaciones posteriores -como le sucedió al mismo Ortega--, algo que parece que empieza a paliarse, aunque de un modo más lento del que sería deseable. Y digo esto porque la lectura de estos clásicos hispanos encierra tesoros inesperados sobre algunos de los debates más importantes de la filosofía contemporánea. Ese es el caso, me parece a mí, de la posición que cabe atribuir a José 
Gaos en el asunto de la diversidad cultural, al menos en la forma, probablemente peculiar, que tengo de leerlo y, si se me permite la expresión, "actualizarlo".

En efecto, creo que el interés del planteamiento gaosiano con respecto al asunto del que se ocupa este trabajo reside en que se aleja en algunos aspectos muy relevantes tanto de Ortega, por lo menos del Ortega que podría considerarse más husserliano, como, desde luego, del propio Husserl. Si en los dos primeros, aunque con matices claramente diferenciados, es la fuerza más o menos temperada de la racionalidad filosófica la que otorga identidad a la cultura europea y sirve para discriminar entre culturas, en Gaos se produce un giro de hondo calado sobre las posibilidades de ésta y piensa, igual que los representantes actuales del pensamiento débil --Rorty o Vattimo- - que solo asumiendo conscientemente la debilidad de la razón, la impotencia de la filosofía, es posible discriminar entre buena y mala diversidad y convivir libremente en una sociedad tolerante ${ }^{9}$.

La confrontación de José Gaos con la diversidad humana está relacionada, en primer lugar, no tanto con la diversidad cultural en sí, sino con un hecho radical que afecta a la propia filosofía: su inquebrantable pluralidad e historicidad. Para Gaos, la línea medular de la filosofía desde su nacimiento en Grecia está conformada por la metafísica, un tipo de discurso cuyo objetivo último es alcanzar mediante la razón el fundamento último de todo cuanto hay con el propósito de poder orientar nuestras vidas. Sin embargo, si echamos un vistazo a la historia de la filosofía, el espectáculo poco edificante al que asistimos es la anarquía de los sistemas filosóficos, su discrepancia e incompatibilidad manifiesta a la hora de fijar los primeros principios supuestamente evidentes de lo real. Tal anarquía parece indicar la impotencia de la razón para alcanzar el fundamento, parece desmentir el viejo y querido lema racionalista según el cual el correcto y lúcido ejercicio de la facultad racional habría de llevar por fuerza al establecimiento incontestable de una serie de principios en los que todos deberíamos estar de acuerdo (cf., por ejemplo, Gaos, 1982a, 60-65).

Pero si la metafísica no puede cumplir su función fundamentadora, ¿qué nos muestran los sucesivos y radicalmente diferentes relatos de los filósofos sobre el fundamento más allá de la imposibilidad de llevarlo a cabo? La desconcertante y provocadora respuesta de Gaos es que tales narraciones no son otra cosa que "confesiones personales" (Gaos, 1982b, 416-429), visiones o perspectivas de sentido destiladas por la intimidad de cada pensador y traducidas en conceptos; relatos de vida más o menos coherentes que muestran, hasta donde es posible, la individualidad de cada uno de sus hacedores y el sentido con el que han afrontado la existencia ${ }^{10}$. Lo mismo, dice el pensador transterrado, sucede con las diferentes

9 He tratado de hacer una lectura “debilitante” de Gaos en Díaz Álvarez, 2016, 137-156. Sobre la relación GaosOrtega, cf., Lasaga, 2013, 9-55. Esa misma relación, en una perspectiva distinta, en Díaz Álvarez, 2018, 37-53. Para una breve presentación canónica de la filosofía de Gaos, cf., Zirión, 2009, 535-544. Otra apretada síntesis de la obra gaosiana, pero que incide en la línea del debilitamiento de la razón que aquí se defiende, puede verse en Díaz Álvarez, 2011b, 55-66. Una biografía intelectual imprescindible es la de Aurelia Valero, José Gaos en México. Una biografía intelectual 1938-1969 (cf., Valero, 2015). Y un libro que conserva una gran fuerza es el de Vera Yamudi, José Gaos. El hombre y su pensamiento (Yamudi, 1980). Para una penetrante reactualización de su pensamiento llevada a cabo por uno de nuestros mejores filósofos contemporáneos recientemente fallecido ver, Muguerza, 2001, 183-218 y el ya citado Muguerza, 2010, 56-81. Por último, una buena colección de artículos sobre diversos aspectos del pensamiento del ilustre transterrado en Sevilla, 2008.

10 Sobre esta crucial tesis del pensamiento gaosiano es preciso recomendar el texto de Agustín Serrano de Haro “Autobiografia e ricerca filosofica. Il caso di José Gaos” (Serrano de Haro, 2016, 125-135). 
culturas. El mundo es en realidad una pluralidad de mundos, o mejor dicho, la realidad y la verdad son plurales, responden a aperturas de sentido o perspectivas diferentes y por eso se constelan en sistemas de creencias también distintos que no pueden ser unificados por la facultad de la razón (cf. Gaos, 2009, 47).

¿Pero si tal facultad no puede alcanzar una unificación última del sentido, si la imposibilidad del fundamento lo que hace es proclamar la diseminación de las opiniones y visiones del mundo, no nos condena Gaos al más absoluto escepticismo, al relativismo, a la arbitrariedad más grosera? ¿No le incapacita su posición para distinguir entre la buena y la mala diversidad? ${ }^{11}$ Creo que el pensador hispano se sorprendería mucho ante la acusación de relativismo. Su asunción de la quiebra de la metafísica y el subsiguiente estallido de la pluralidad no es una celebración irrestricta de las diferencias, sino la constatación de lo que él entiende como un dato fenomenológico radical. En el principio no fue el logos, sino la pluralidad, y la razón no tiene potencia suficiente para remontarla. En efecto, lo que cabalmente hace el filósofo con su crítica al discurso metafísico es asumir la fragilidad y limitación del conocimiento humano, nuestra contingencia. Para Gaos, como para su maestro Ortega, hoy ya no es posible aceptar que tenemos acceso al punto de vista de Dios, ni siquiera de modo asintótico. Somos humanos, no dioses, y no podemos imbuirnos de los atributos que no son propiamente nuestros. Se trata, pues, de asumir, de una vez por todas, nuestra humanidad, y de la mano de ella, que todas las perspectivas o creencias que configuran el sentido personal o comunitario son contingentes. Es precisamente la experiencia y la conciencia de esta contingencia la que podría permitir un verdadero diálogo y encuentro con el otro, la que quizá podría facultarnos, apunta Gaos, para una conversación verdaderamente humana. Enredados en ella podríamos rebajar el grado de violencia y contemplar el espectáculo del mundo y la pluralidad que le es propia sin angustia, con una, y es expresión suya, "indulgente y melancólica serenidad filosófica" (Ibídem., 47). A la filosofía de la soberbia, la metafísica, "cabe oponer una 'filosofía' de la melancólica serenidad" (Ibídem., 47). Una filosofía que ante la diversidad del mundo trata de volver "a los hombres más juiciosos de lo que han sido hasta aquî́" (Ibídem., 49) porque les hace reparar en lo poco razonable que resulta intentar imponer una perspectiva que cree llevar en su seno los principios últimos de lo real ${ }^{12}$. Puesto que todas ellas son contingentes, todos deberíamos ser tolerantes y gestionar nuestras diferencias teniendo presente que las ideas sobre el mundo y los humanos son siempre penúltimas. En un contexto semejante, de lo que se trata es de llegar a pactos razonados y siempre revisables que nos permitan desarrollar del modo más amplio posible nuestros diversos y muchas veces incompatibles modos de entender la plena humanidad. En

11 Eso es lo que pensaron muchos de sus más destacados discípulos. Un documento enormemente esclarecedor de lo que acabo de afirmar es la introducción que Alejandro Rossi pone a la antología de Gaos que él mismo edita y que lleva por título "Una imagen de José Gaos” (Rossi, 1989, 11-17).

12 No puedo entrar en el presente texto en la genial vinculación que Gaos hace entre filosofía, en sentido metafísico - fundacionalista - y violencia. Simplemente me gustaría señalar que para el pensador hispano el origen de aquella hay que situarlo en la soberbia, en el afán arcóntico de dominio derivado, en el fondo, de la idea de que podemos superar la finitud y la contingencia y alcanzar, o estar en disposición de alcanzar — aunque sea de modo ideal—, un saber "científico" sobre la realidad. Pero si la soberbia se conecta con la superación de la finitud, la razón última para querer superarla y no convivir con ella es la angustia que nos genera asumir nuestra inalienable individualidad, la radical soledad que es nuestra vida. Sobre estos asuntos y sobre una posible lectura debilitante del filósofo hispano pueden verse los textos del presente autor recogidos en la nota 9. 
definitiva, para Gaos, el límite a la diversidad cultural estaría en el respeto que nos debemos unos humanos a otros, un respeto derivado de la conciencia de nuestra propia finitud: "Y contra la voluntad de poder [de la soberbia metafísica] cabe sentir en la luminosidad de la evidencia el valor de la plural riqueza del universo, comprensiva de la rica pluralidad de las personalidades individuales y colectivas, razas, pueblos, culturas. Quien siente tal valor no puede menos de sentir la repugnancia ante toda dominación de los demás y, muy en primer término la dominación de nadie por él mismo, correlativa en la complacencia de aquella rica pluralidad, y de aquella plural riqueza del universo, que siente que le enriquecen a él mismo por lo menos con el atisbo de las diferencias vagamente insinuadas en lo más hondo de las intimidades ajenas. Quien tal siente tampoco puede menos de concebir como ideal una única unanimidad en el valor del respeto de cada ser humano para cada uno de los demás, el gozo de todos en la comunión de tal unanimidad" (Ibídem., 47).

\section{A modo de conclusión. Los mapas del laberinto. Entre el fundamento racional y la debilidad del pensar}

En los apartados precedentes he intentado mostrar, espero que con una cierta fortuna, alguna de las formas en que tres grandes filósofos del siglo $\mathrm{XX}$, con evidentes conexiones intelectuales entre sí, han tratado de hacer frente al laberinto de la diversidad cultural. Permítaseme, ya para terminar, hacer una pequeña valoración conjunta de los tres mapas que he pretendido dibujar.

Como indiqué en su momento, el modelo husserliano y el orteguiano contenido en Las Atlántidas tienen, en principio, bastantes cosas en común. No en vano Ortega estudió y conoció bien la fenomenología de Husserl, al que consideraba uno de sus maestros, y saludó la aparición de las dos primeras partes de La crisis de las ciencias europeas, las únicas que conoció, como un trabajo en la línea de lo que estaba haciendo con su filosofía de la razón histórica ${ }^{13}$.

En efecto, tanto Ortega como Husserl creen que la mirada crítica que nace con la filosofía es el meollo de "occidente" y que tal mirada, con sus ideales de libertad, autonomía y razonabilidad, coagula un aspecto esencial de lo humano que garantiza que podamos discriminar entre buena y mala diversidad. Nada que conculque, como diría Husserl, la Urstiftung, la fundación originaria de ese ideal podrá ser aceptado como válido. Sin embargo, Ortega, incluso el Ortega más husserliano, es un filósofo cuya idea de racionalidad está ampliamente horadada por la contingencia. Es una razón, podríamos decir, sometida a una amplia cura de adelgazamiento hecha a base de finitud e historicidad; es una razón histórica. Por eso le fascinó e influyó profundamente, como a tantos "discípulos" de Husserl, la lectura de Ser y

13 Sobre este asunto, cf., Ortega y Gasset, 2006a, 24-29. Para la relación de Ortega y la fenomenología husserliana son imprescindibles los trabajos de Javier San Martín. La summa de esa investigación se encuentra en San Martín, 2012. También es preciso mencionar los excelentes textos de Miguel García-Baró. Véase, por ejemplo, los recogidos en Sentir y pensar la vida. Ensayos de fenomenología y filosofía española (García-Baró, 2012). Asimismo, son de gran profundidad filosófica los múltiples y pioneros escritos de Pedro Cerezo. Ver, entre otros, el ya clásico Voluntad de aventura (Cerezo, 1984, 191-338). Por mi parte, he abordado la lectura orteguiana de $L a$ crisis en Díaz Álvarez, 2003, 44-46. Y la relación de Ortega y la fenomenología husserliana en Díaz Álvarez, 2013, 3-18 y Díaz Álvarez/Brioso, 2018, 373-386. 
tiempo de Heidegger. Dicho de otro modo, la razón orteguiana se comprende como mucho menos poderosa que la del viejo maestro alemán. En el pensador madrileño no hay la asunción explicita, que parece haber en Husserl, de que la fuerza de la razón debería, idealmente al menos, deshacer las discrepancias o desacuerdos humanos si hacemos un ejercicio pulcro, cuidadoso y honesto de nuestro preciado don racional. En resumen, la razón común que descubre occidente con la filosofía es para Ortega una razón que discrimina entre buena o mala diversidad porque siempre rechazará las diferencias que conculquen el espacio en el que se desarrolla la propia labor de la vida racional, ese ámbito donde entran en conflicto razonado las diversas perspectivas sobre lo humano, pero tal razón carece de la dirección y la potencia teleológica que está presente en la Vernunft husserliana ${ }^{14}$.

En cuanto a Gaos, parece claro que todavía fue más allá que su maestro en el debilitamiento de la razón filosófica, por lo menos en lo que respecta al Ortega más influenciado por la fenomenología que aquí he contemplado. Si en el autor de Las Atlántidas podíamos ver una racionalidad mucho más trufada de contingencia que en Husserl, en Gaos no queda prácticamente nada de la vieja potencia de la razón como medio para orientarnos en la inmensa diversidad personal y cultural que nos rodea. Gaos radicaliza el perspectivismo de su maestro, la pluralidad últimamente no reconciliable. Por eso hace de la necesidad virtud, y convierte la impotencia de la razón o, mejor dicho, la conciencia de la impotencia de la razón, en el instrumento que establece la diferencia entre buena y mala diversidad.

Expresado de un modo muy simple, si Husserl pensaba que la razón podía trazar un mapa nítido y bien perfilado en el que la racionalidad filosófica iluminaría con claridad meridiana la resolución de los problemas planteados por la diversidad cultural, Ortega incluso el más husserliano-- creyó que tal mapa era bastante más difuso y la luz mucho menos fuerte de lo que pensaba su maestro. Quizá podríamos resolver bastantes conflictos con su ayuda, pero otros muchos quedarían sin esclarecer. En cualquier caso, la apertura del espacio de la vida racional y su no conculcación por ninguna de las perspectivas, era la garantía máxima que teníamos para descartar la mala diversidad. Por fin, para Gaos, el mapa iluminado por la razón no puede resolver, en el sentido estricto del término, prácticamente ninguno de los conflictos dignos de tal nombre. Pero es precisamente de aquí de donde extraemos la lección. La impotencia de la razón debería producir, paradójicamente, el salto evolutivo que Husserl achaca al descubrimiento del ejercicio de la racionalidad y volvernos más tolerantes.

La pregunta lógica después de la cartografía realizada es ¿qué mapa resulta más fiable?, ¿cuál permitirá alcanzar el objetivo para el que lo diseñaron sus autores? En suma, ¿cuál nos orientará mejor en el laberinto de la diversidad cultural? Después de años de claras simpatías husserlianas y de confianza en la potencia de la razón y la idea de fundamentación racional, me inclino cada vez más a pensar que el viejo y gran maestro alemán quizá subestimó la fuerza de la contingencia y la pluralidad. Cada vez albergo más dudas no sobre la idea de Europa como ejercicio crítico de la razón, como defensa de la libertad, la autonomía y el diálogo, sino sobre el hecho de que montados en su noble ejercicio los humanos honestos puedan alcanzar acuerdos incontestables en su "verdad". Creo, al res-

14 Esta tendencia va a acentuarse más y más a lo largo de los años treinta con la aparición de lo que en la nota 3 he considerado como "giro historicista". 
pecto, que es bueno tener siempre presente la advertencia de Ortega, que Gaos radicaliza, de que no estamos hechos para lo eterno, de que no podemos alcanzar el punto de vista de Dios. Y que cuando lo hemos intentado las cosas nunca terminaron bien. De todas formas, y en tiempos cada vez más idolátricos culturalmente, no deberíamos dejar de darle vueltas a la propuesta husserliana, una propuesta, tampoco debe olvidarse nunca, que alcanza toda su profundidad y potencia con respecto a estos temas en la época en que los nazis dominan Alemania y arrastran al que probablemente fue el pueblo más culto del momento a la mayor ignominia moral de la historia de la humanidad. Un fiel y destacado discípulo de Husserl, Aron Gurwitsch, expresó en más de una ocasión que semejante barbarie se había podido producir precisamente por la renuncia de la filosofía - una filosofía dominada a la sazón por la obra de Martín Heidegger- a la idea de fundamentación racional ${ }^{15}$. Y aunque ya no creo en la alternativa o fundamento o barbarie, no seré yo quien desaconseje el volver a mirar una y otra vez el mapa husserliano.

\section{Referencias}

Cerezo, P. (1984), Voluntad de aventura. Aproximamiento crítico al pensamiento de Ortega y Gasset, Barcelona: Ariel.

De Mingo, A. (2017), Ciencia objetiva y mundo de la vida. Husserl vs. Galileo y Copérnico, Sevilla: Fénix Editora.

Derrida, J. (1987), De l'esprit: Heidegger et la question, Paris: Galilée.

De Haro Honrubia, A. (2012), "La antropología social en la obra de Ortega. Su contribución a la etnografía moderna", Anales del Seminario de Historia de la Filosofía, 29, 1, pp. 217-240.

Díaz Álvarez, Jesús M. (2003), Husserl y la historia. Hacia la función práctica de la fenomenología, Madrid: UNED.

Díaz Álvarez, Jesús M. (2007), “Son todas las épocas y culturas humanas iguales ante os ojos de Dios. Husserl y el problema del eurocentrismo?", Phainomenon. Revista de fenomenología, 14, pp. 157-169.

Díaz Álvarez, Jesús M. (2011a), "Fenomenólogos en tiempos sombríos. La discusión de Aron Gurwitsch y Dorion Cairns sobre el nazismo", Investigaciones Fenomenológicas, 3 Monográfico, pp. 119-139.

Díaz Álvarez, Jesús M. (2011b), "Presentación y actualidad de José Gaos”, Boletín de estudios de filosofía y cultura Manuel Mindán, 6, pp. 55-66.

Díaz Álvarez, Jesús M. (2012), "Más allá del relativismo y del racionalismo. Algunas consideraciones sobre la teoría de la perspectiva en El tema de nuestro tiempo", en López Sáenz, C./Díaz Álvarez, Jesús M. (eds.). Racionalidad y relativismo. En el laberinto de la diversidad, Madrid: Biblioteca Nueva, pp. 109-128.

15 Un documento ejemplar y especialmente revelador de la tesis gurwitschiana es el intercambio epistolar que este fiel seguidor de Husserl mantiene con otro fenomenólogo no menos cercano al maestro alemán, Dorion Cairns. Las cartas fueron recogidas en su día por el añorado Lester Embree, albacea de ambos en "Two Husserlians Discuss Nazism: Letters between Dorion Cairns and Aron Gurwitsch in 1941" (cf., Embree, 1991, 77-105). Por su parte, me he ocupado de este brillante y revelador intercambio en Díaz Álvarez, 2011a, 119-139. 
Díaz Álvarez, Jesús M. (2013), “José Ortega y Gasset and Human Rights”, en Embree, L./ Nenon, T. (eds.). Husserl's Ideen, New York/London: Springer, pp. 3-18.

Díaz Álvarez, Jesús M. (2015), “ ¿Una razón sin astucia? Revisitando el tópico fenomenología transcendental e historia”, Escritos de filosofía-Segunda serie, pp. 81-105.

Díaz Álvarez, Jesús M. (2016), "La filosofia della serenità melancolica contro la superbia filosofica. Su José Gaos e l'indebolimento del pensiero", en Parente, L. (ed.), La scuola di Madrid. Filosofia spagnola del XX secolo, Milano-Udine: Mimesis, pp. 137-156.

Díaz Álvarez, Jesús M./Brioso, J. (2018), “El filósofo y sus filosofías. Ortega, la fenomenología y algo más”, en Díaz Álvarez, Jesús M./Lasaga Mediana, J. (eds.), La razón y la vida. Escritos en homenaje a Javier San Martín, Madrid: Trotta, pp. 373-386.

Embree, L. (1991), “Two Husserlians Discuss Nazism: Letters between Dorion Cairns and Aron Gurwitsch in 1941", Husserl Studies, 8, pp. 77-105.

Gaos, J. (1982a), Confesiones Profesionales. Aforística (Obras Completas), Tomo XVII, México: UNAM.

Gaos, J. (1982b), De la filosofía (Obras Completas), Tomo XII, México: UNAM

Gaos, J. (2009), "Discurso de Filosofía”, en Obras Completas, Tomo XV, México: UNAM, pp. 35-50.

García-Baró, M. (2012), Sentir y pensar la vida. Ensayos de fenomenología y filosofía española, Madrid: Trotta.

García-Baró, M. (2015), Husserl y Gadamer, Barcelona: Batiscafo.

Hart, J. (1992), “The Rationality of Culture and the Culture of Rationality: Some Husserlian Proposals", Philosophy East and West, 42, No 4, pp. 643-664.

Husserl, E. (1976), Die Krisis der europäischen Wissenschaften und die transzendentale Phänomenologie. Eine Eileitung in de phänomenologische Philosophie (Husserliana VI), Den Haag: Kluwer.

Lasaga, J. (2013), “Introducción”, en Gaos, J., Los pasos perdidos. Escritos sobre Ortega y Gasset, Madrid: Biblioteca Nueva, pp. 9-55.

López Sáenz, C. (2015), "Interculturalism as an Articulation of Diversity. A Generative Phenomenological Approach", The Yearbook on History and Interpretation of Phenomenology, 3, pp. 117-138.

Mate, R. (1998), Heidegger y el judaísmo. Y sobre la tolerancia compasiva, Barcelona: Anthropos.

Muguerza, J. (1991), “Kant y el sueño de la razón”, en Thiebaut, C. (ed.), La herencia ética de la Ilustración, Barcelona: Crítica, 9-36.

Muguerza, J. (1998a), El puesto del hombre en la cosmópolis, Madrid: UNED.

Muguerza, J. (1998b), "El tribunal de la conciencia y la conciencia del tribunal”, en Váquez, R. (ed.), Derecho y moral. Ensayos sobre un debate contemporáneo, Barcelona: Gedisa, 183-211.

Muguerza, J. (2001), “Individualidad y filosofía. (Variaciones sobre un tema de José Gaos en homenaje a Fernando Salmerón)", en Rodríguez de Lecea, T. (ed.), En torno a José Gaos, València: Institució Alfons el Magnànim, pp. 183-218.

Muguerza, J. (2009), "Verdad, consenso y tolerancia. La incomodidad del 'lugar del otro"”, en VV.AA., La audacia de la libertad. Homenaje a Agustín Andreu, Valencia: Universidad Politécnica de Valencia, pp. 9-25. 
Muguerza, J. (2010), “Ortega en Latinoamérica: El legado filosófico de José Gaos”, en Sánchez Cuervo, A./Hermida de Blas, F. (Coords.), Pensamiento exiliado español. El legado filosófico del 39 y su dimensión iberoamericana, Madrid: Biblioteca Nueva/CSIC.

Ortega y Gasset, J. (2005), "Las Atlántidas", en Obras Completas, Tomo III, Madrid: Taurus, pp. 743-774.

Ortega y Gasset, J. (2006a), “Apuntes sobre el pensamiento, su teurgia y su demiurgia”, en Obras Completas, Tomo VI, pp. 3-41.

Ortega y Gasset, J. (2006b), "Prólogo a Historia de la Filosofía de Émile Bréhier", en Obras Completas, Tomo VI, pp. 135-171.

Ortega y Gasset, J. (2016), Las Atlántidas y otros textos antropológicos (Edición de José Ramón Carriazo Ruiz), Madrid: Tecnos.

Pereña, F. (2012), "Racionalidad universal y diversidad cultural”, en López Sáenz, M./Díaz Álvarez, J.M., Racionalidad y relativismo. En el laberinto de la diversidad, Madrid: Biblioteca Nueva, pp. 177-191.

Rossi, A. (1989), “Una imagen de José Gaos”, en Gaos, J., Filosofía de la filosofía (Antología y presentación de Alejandro Rossi), Barcelona: Crítica, pp. 11-17.

San Martín, J. (2007), Para una filosofía de Europa. Ensayos de fenomenología de la historia, Madrid: Biblioteca Nueva.

San Martín, J. (2012), La fenomenología de Ortega y Gasset, Madrid: Biblioteca Nueva.

Savater, F. (2004), "Idolatría de la diversidad", El País, 1 de julio de 2004. Disponible en: https://elpais.com/diario/2004/07/01/opinion/1088632807_850215.html

Serrano de Haro, A. (2011), "Husserl y el sentido de la historia a la altura de 1923", Laguna, 28, pp. 9-22.

Serrano de Haro, A. (2016), “Autobiografia e ricerca filosofica. Il caso di José Gaos”, en Parente, L. (ed.), La scuola di Madrid. Filosofia spagnola del XX secolo, Milano-Udine: Mimesis, pp. 125-135.

Sevilla, S. (2008), Visiones sobre un transterrado. Afán de saber acerca de José Gaos, Madrid: Iberoamericana.

UNESCO (2001), "Declaración Universal de la UNESCO sobre la Diversidad Cultural", UNESCO, 2 de noviembre de 2001. Disponible en: http://portal.unesco.org/es/ev.phpURL_ID=13179\&URL_DO=DO_TOPIC\&URL_SECTION=201.html

Valero, A. (2015), Jose Gaos en México. Una biografía intelectual 1938-1969, México DF: El colegio de México.

Yamudi, V. (1980), José Gaos. El hombre y su pensamiento, México: UNAM.

Zirión, A. (2009), "José Gaos (1900-1969)", en Garrido, M./Orringer, N./Valdés L./Valdés, M. (coords.), El legado filosófico español e hispanoamericano del siglo XX, Madrid: Cátedra, pp. 535-544. 